\title{
PENGARUH MOBILISASI PERGELANGAN TANGAN SETELAH DIBERIKAN ULTRASOUND TERHADAP PENURUNAN NILAI NYERI PASIEN CARPAL TUNNEL SYNDROME
}

\section{The Effect of Wrist Mobilization after Ultrasound Therapy to Decrease Pain of Patients with Carpal Tunnel Syndrome}

\author{
Raditya Kurniawan Djoar ${ }^{1}$, Anastasia Putu Martha Anggarani ${ }^{2}$ \\ 1. Program Studi Keperawatan STIKES Katolik St. Vincentius a Paulo \\ 2. Program Studi Fisioterapi STIKES Katolik St. Vincentius a Paulo \\ Email: radit_stikvinct@yahoo.com
}

\begin{abstract}
ABSTRAK
Carpal Tunnel Syndrome (CTS) merupakan bentuk cedera tekanan yang berulang pada nervus medianus dan merupakan syndrome penjepitan saraf yang paling sering ditemukan. Kejadian CTS ini telah menjadi pusat perhatian peneliti karena merupakan salah satu jenis cummulative trauma disorders (CTD) yang paling banyak dijumpai. Karena permasalahan tersebut, akibatnya pergelangan tangan menjadi terbatas dan tidak mampu berfungsi sebagaimana mestinya sehingga berpengaruh terhadap pekerjaan sehari-hari. Tujuan dari penelitian ini adalah menganalisis pengaruh penambahan intervensi berupa mobilisasi saraf medianus, carpal dan tendon gliding setelah diberikan Ultrasound terhadap penurunan nilai nyeri CTS. Penelitian ini merupakan penelitian eksperimen dengan pendekatan quasi eksperimental, dengan desain penelitian pre and post test two groups design

Populasi penelitian ini adalah pasien CTS di RSUD Sidoarjo sebanyak 70 orang yang dibagi dalam dua kelompok yaitu kelompok 1 yang mendapatkan terapi ultrasound dan kelompok 2 yang mendapatkan terapi ultrasound serta ditambahkan dengan mobilisasi saraf medianus, carpal dan tendon gliding. Uji statistic yang digunakan adalah independent $\mathrm{t}$ test. Hasil penelitian menunjukan bahwa terdapat perbedaan yang signifikan antara nilai nyeri pada kelompok yang diberikan ultrasound dan kelompok yang diberikan penambahan dengan mobilisasi saraf medianus, carpal dan tendon gliding (Asymp. Sig 2-tailed 0,00). Penurunan nyeri pada kelompok ini lebih significant dikarenakan penggunaan kombinasi dari intervensi tersebut. Latihan mobilisasi saraf medianus dapat membantu mengembalikan aliran pembuluh darah balik vena dari saraf medianus sehingga mengurangi tekanan di dalam epineurium sehingga mengurangi nyeri dengan ditambah latihan tendon gliding dapat mengembalikan aliran pembuluh darah balik vena dari saraf medianus sehingga mengurangi tekanan di dalam epineurium sehingga nyeri berkurang.
\end{abstract}

Kata Kunci : CTS, mobilisasi saraf medianus, carpal dan tendon gliding

\section{ABSTRACT}

Carpal Tunnel Syndrome (CTS) is a form of recurring damage to the median nerve and is the nerve syndrome that is most commonly found. CTS was attention of researchers because it is one of the most common types of cumulative trauma disorders (CTD). Because of these problems, were effected for activity for the daily work. The purpose of this study was to analyze interventions involving the mobilization of the median nerve, carpal and tendon gliding after being given an ultrasound to reduce pain of patient with CTS. This research was experimental research with quasi-experimental, pre-post test design and two groups design

The population of this study was CTS patients in RSUD Sidoarjo. Respondents was 70 patient divided into two groups: group 1 who received ultrasound therapy only and group 2 who received ultrasound therapy and median nerve mobilization, carpal and tendon gliding. The statistical test used was an independent $t$ test. The results showed that there was a significant difference between the values in the group given ultrasound therapy and the group given by median nerve mobilization, carpal and tendon gliding (Asymp. Sig 2-tailed 0.00). Pain Reducing in this group is significant because using a combination. Median nerve mobilization exercises can increase nerve blood flow from the median nerve thereby reducing pressure on the epineurium, and gliding 
exercises which can be used to drain venous blood back from the nerves the median reduces the pressure inside the epineurium and reducing the pain.

Keywords : CTS, mobilization of the median nerve, carpal and tendon gliding

\section{PENDAHULUAN}

Carpal Tunnel Syndrome (CTS) didefinisikan suatu bentuk cedera tekanan yang berulang pada nervus medianus dan merupakan syndrome penjepitan saraf yang paling sering ditemukan (Lubis et all, 2016). Nervus medianus rentan terhadap kompresi dan cedera pada pergelangan tangan (Syahrul, 2014). Setiap penggunaan tangan secara intensif seperti menggenggam, memutar, atau menekuk, secara terus menerus akan memperparah keadaan ini (Lubis et all, 2016). Biasanya CTS terjadi pada perempuan berusia 30 dan 60 tahun (Lubis et all, 2016) dengan tingkat prevalensi pada populasi umum 3,7 - 5,8 \% (Arul, 2016). Hal ini dikarenakan wanita memiliki terowongan karpal yang lebih kecil dibandingkan pria (Saerang, 2015). Kejadian CTS ini telah menjadi pusat perhatian peneliti karena merupakan salah satu jenis cummulative trauma disorders (CTD) yang paling banyak dijumpai (Kisner, 2014). Karena permasalahan tersebut, akibatnya pergelangan tangan menjadi terbatas dan tidak mampu berfungsi sebagaimana mestinya sehingga berpengaruh terhadap pekerjaan sehari-hari (Saerang, 2015). Umumnya $C T S$ terjadi secara kronis dimana terjadi penebalan fleksor retinakulum yang menyebabkan tekanan terhadap nervus medianus.Tindakan berupa Ultrasound dan elektroterapi pada beberapa pelayanan di rumah sakit pada kasus carpal tunnel syndrome mendapatkan hasil yang cukup efektif untuk mengurangi nyeri pada kasus CTS (Chan, 2014). Namun sebagian besar pasien masih merasakan nyeri di akhir periode terapi. Jika ditambahkan dengan mobilisasi saraf, carpal dan tendon gliding dapat membantu pengembalian fungsi dan gerak fisiologis dari nervus medianus sehingga dapat menurunkan nyeri lebih efektif, dengan mobilisasi saraf maka diharapkan suplai darah dan sirkulasi aksoplasma akan membaik, dapat melakukan mobilisasi jaringan saraf, jaringan konektif saraf dan restriksi saraf serta akan menstimulasi penyembuhan jaringan tersebut (Kisner, 2014). Observasi yang dilakukan di RSUD Sidoarjo mengambarkan total pasien CTS 78 orang. Tindakan yang diberikan untuk kasus CTS di RS tersebut adalah pemberian Ultrasound dan Elektroterapi. Hasilnya, $75 \%$ pasien masih mengeluh nyeri sampai di akhir periode terapi. Oleh karena itu peneliti akan menganalisis pengaruh penambahan intervensi berupa mobilisasi saraf medianus, carpal dan tendon gliding setelah diberikan Ultrasound dan elektroterapi terhadap penurunan nilai nyeri CTS. Pengaruh penambahan intervensi berupa mobilisasi saraf medianus, carpal dan tendon gliding harus segera diketahui karena apabila tidak, pasien dengan CTS hanya akan diberikan terapi dengan Ultrasound dan elektroterapi dan akan tetap mengeluhkan nyeri walaupun periode terapi telah selesai sehingga akan mengalami keterbatasan dalam melakukan aktivitas fungsional.

\section{METODE}

Penelitian ini merupakan penelitian eksperimen dengan pendekatan quasi eksperimental, dengan desain penelitian pre and post test two groups design

Populasi penelitian ini adalah pasien CTS di RSUD Sidoarjo deengan jumlah responden sebanyak 70 orang dengan criteria: menjalani perawatan jalan berupa Ultrasound Therapy, mendapat nilai positif untuk upper neural tension test 1 , bersedia menjadi subyek penelitian dengan tuntas dari awal hingga akhir penelitian, tidak sedang mengonsumsi obat pengurang nyeri pada saat penelitian berlangsung. Responden dalam penelitian ini dibagi dalam dua kelompok dimana masing-masing kelompok beranggotakan 35 orang. Kelompok pertama responden yang memenuhi criteria inklusi Mobilisasi pergelangan yang dilakukan pada responden meliputi mobilisasi syaraf selama 5 detik, mobilisasi carpal sebanyak 6-10 kali, serta tendon gliding (Kisner, 2014). 
Pemberian mobilisasi ini dilakukan paling sedikit tiga kali selama 1 bulan saat pasien control ke RS serta pasien diajarkan untuk melakukan tindakan mobilisasi selama dirumah. Pemeriksaan derajat nyeri dengan menggunakan NPRS dengan prosedur pengukuran yaitu pasien diminta untuk membuat tiga peringkat nyeri, nyeri yang dialami saat ini, nyeri yang dirasakan paling ringan dan paling buruk selama 24 jam terakhir. Instruksikan kepada pasien untuk menunjukkan intensitas nyeri pada skala 0 (tidak ada rasa sakit) ke 10 (nyeri terburuk yang bisa dibayangkan) dengan rating angka $0=$ tidak ada nyeri, 1 sampai 3 = nyeri ringan, 4 sampai $6=$ nyeri sedang, 7 sampai $10=$ nyeri berat (Trisnowiyanto, 2012).

Untuk melihat Pengaruh Penambahan Mobilisasi Pergelangan Tangan Setelah Diberikan Ultrasound Terhadap Penurunan Nilai Nyeri CTS dianalisis menggunakan program SPSS dengan menggunakan uji komparatif uji t tidak berpasangan.

\section{HASIL DAN PEMBAHASAN \\ HASIL}

Pada bagian ini akan disajikan karakteristik responden berdasarkan usia, jenis kelamin, riwayat jatuh menumpu, aktivitas fisik seharihari, serta karakteristik nyeri pasien CTS. Pada tabel 1 menunjukkan bahwa sebagian besar responden kelompok 1 berusia lebih dari 40 tahun $(97,15 \%)$, berjenis kelamin perempuan $(85,72 \%)$, tidak memiliki riwayat jatuh menumpu (54,35), serta aktivitas sehari hari sebagai Ibu Rumah tangga sebesar 60\%. Pada tabel 2 dapat diinterpretasikan bahwa sebagian besar responden kelompok 2 berusia 40 tahun atau lebih $(85,7 \%)$, berjenis kelamin perempuan $(77,14 \%)$, tidak memiliki riwayat jatuh menumpu $(68,6)$, serta aktivitas sehari hari sebagai pegawai negri/swasta 57,14\%.

Tabel 1 Karakteristik Responden Kelompok 1 (Pemberian Ultrasound)

\begin{tabular}{|c|c|c|c|}
\hline No & Karakteristik & Jumlah & Prosentase \\
\hline \multirow[t]{3}{*}{1.} & Usia & & \\
\hline & $<40$ tahun & 1 & 2,85 \\
\hline & $\geq 40$ tahun & 34 & 97,15 \\
\hline \multirow[t]{3}{*}{2.} & Jenis Kelamin & & \\
\hline & Laki-laki & 5 & 14,28 \\
\hline & Perempuan & 30 & 85,72 \\
\hline \multirow[t]{3}{*}{3} & Riwayat Jatuh Menumpu & & \\
\hline & Pernah & 16 & 45,7 \\
\hline & Tidak Pernah & 19 & 54,3 \\
\hline \multirow[t]{4}{*}{4} & Aktivitas sehari-hari & & \\
\hline & Ibu Rumah Tangga & 21 & 60 \\
\hline & Pegawai Negri/swasta & 12 & 34,3 \\
\hline & Lain-lain & 2 & 5,7 \\
\hline \multicolumn{4}{|c|}{ Tabel 2 Karakteristik Responden Kelompok 2 (Pemberan ultrasound dan mobilisasi) } \\
\hline No & Karakteristik & Jumlah & Prosentase \\
\hline \multirow[t]{3}{*}{1.} & Usia & & \\
\hline & $<40$ tahun & 5 & 14,3 \\
\hline & $\geq 40$ tahun & 30 & 85,7 \\
\hline \multirow[t]{3}{*}{2.} & Jenis Kelamin & & \\
\hline & Laki-laki & 8 & 22,86 \\
\hline & Perempuan & 27 & 77,14 \\
\hline \multirow[t]{3}{*}{3} & Riwayat Jatuh Menumpu & & \\
\hline & Pernah & 11 & 31,4 \\
\hline & Tidak Pernah & 24 & 68,6 \\
\hline \multirow[t]{4}{*}{4} & Aktivitas sehari-hari & & \\
\hline & Ibu Rumah Tangga & 14 & 40.01 \\
\hline & Pegawai Negri/swasta & 20 & 57,14 \\
\hline & Lain-lain & 1 & 5,7 \\
\hline
\end{tabular}


Tabel 3 Nilai Nyeri

\begin{tabular}{cccccc}
\hline \multicolumn{3}{c}{ Kelompok 1 } & \multicolumn{3}{c}{ Kelompok 2 } \\
\hline \multicolumn{3}{c}{ Mean Nyeri } & \multicolumn{3}{c}{ Mean Nyeri } \\
Pre & Post & Selisih & Pre & Post & Selisih \\
5,37 & 4,54 & 0,83 & 4,48 & 3,11 & 1,37 \\
\hline
\end{tabular}

Pada Tabel 3 dapat di lihat bahwa mean nilai nyeri menunjukkan bahwa pada kelompok ultrasound terdapat selisih antara nilai nyeri sebelum dan setelah dilakukan tindakan sebesar 0,83, sedangkan pada kelompok mobilisasi terdapat selisih nilai nyeri sebelum dan setelah tindakan mobilisasi sebesar 1,37.

Tabel 4 Uji Beda independent t-test

\begin{tabular}{lcc}
\hline Variabel & Perlakuan & $\begin{array}{l}\text { Asymp. Sig } \\
\text { (2-tailed) }\end{array}$ \\
\cline { 1 - 2 } Nyeri & Ultrasound & 0,00 \\
\cline { 2 - 2 } & $\begin{array}{c}\text { Ultrasound }+ \\
\text { Mobilisasi }\end{array}$ \\
\hline
\end{tabular}

Pada uji beda dengan menggunakan uji statistik uji t tidak berpasangan menunjukkan bahwa terdapat perbedaan yang signifikan antara nilai nyeri pada kelompok yang diberikan ultrasound atau elektroterapy dan kelompok yang diberikan Mobilisasi saraf medianus, carpal dan tendon gliding

\section{PEMBAHASAN}

Ditinjau dari usia respoden dalam penelitian ini lebih dari $85 \%$ berada diatas usia 40 tahun dengan $75 \%$ lebih dari respoden berjenis kelamin perempuan. Hal ini sesuai dengan teori yang disampaikan (Kowalak, 2011), bahwa kejadian carpal tunel syndrome (CTS) banyak terjadi pada perempuan berusia 30 dan 60 tahun dengan tingkat prevalensi pada populasi umum 3,7-5,8\%., selain itu pada usia 40 tahun atau lebih merupakan usia paling rentan terjadi CTS karena pada usia tersebut terdapat pengapuran tulang dan pengaruh hormon serta perbedaan anatomi terowongan karpal khususnya pada perempuan (Lubis, et all, 2016). Pada perempuan yang berusia diatas 40 tahun memungkinkan terjadi CTS dikarena adanya perubahan hormon yaitu esterogen yang bisa menyebabkan terjadinya retensi cairan dan pembengkakan pada terowongan karpal sehinga memicu nyeri, disisi lain pengapuran tulang termasuk didalam terowongan karpal dapat mudah terjadi apabila seseorang tersebut berusia lebih dari 40 tahun yang dapat menyebabkan terjadinya nyeri yang merupakan tanda CTS. Apabila ditinjau dari aktivitas sehari-hari dari responden bahwa sebagian besar dari responden bekerja sebagai Ibu Rumah Tangga serta pegawai di kantor dimana pekerjaan mereka membutuhkan aktivitas yang sering dan berulang melibatkan penggunaan pergelangan tangan dan sendi jari. Kegiatan yang melibatkan penggunaan pergelangan tangan, sendi jari seperti kegiatan mengetik dengan posisi keyboard komputer lebih rendah dari pada posisi pergelangan tangan sehingga pergelangan tangan menjadi tertekan, dan posisi mengetik dengan meletakkan keyboard komputer lebih tinggi dari posisi pergelangan tangan sehingga pergelangan tangan dalam posisi tergantung saat mengetik (Saerang et al., 2015:583), mengulek bumbu dengan penggunaan yang butuh tekanan karena alat yang berat (Sabhilia et al., 2011:70), dan kegiatan sehari-harinya lainnya yang melakukan pekerjaannya menggunakan penggulangan pergelangan tangan secara berlebihan (Kurniawan, 2008:35) dapat memicu timbulnya CTS).

Aktivitas yang berlebihan atau berulang pada pergelangan tangan baik secara fleksi ataupun ekstensi dapat menyebabkan tekanan pada nervus medianus dalam terowongan carpal yang dapat menyebabkan peradangan atau pembengkakan sehingga saraf medianus yang lewat melalui terowongan tulang carpal akan mengalami penyempitan dan menimbulkan nyeri dan penurunan rentang gerak.

Pada uji beda menunjukkan bahwa pada kelompok yang diberikan ultrasound serta pada kelompok yang diberikan ultrasound dengan ditambahkan latihan mobilisasi saraf medianus, carpal dan tendon gliding samasama menunjukkan adanya selisih rata-rata antara nyeri pre dan post, dimana pada kelompok ultrasound terdapat selisih nilai rata-rata NPRS pre dan post tindakan sebesar 0,83 , sedangkan kelompok yang lain terdapat selisih nilai rata-rata VAS pre dan post tindakan yang lebih besar yaitu 1,37. 
Berdasarkan uji statistik independent perbedaan pengaruh yang significant antara kelompok ultrasound dan mobilisasi saraf medianus, carpal dan tendon gliding. Hal ini sesuai dengan teori yang dikemukakan oleh Cameron (2009) bahwa Pemberian ultrasound diathermy untuk klien dengan CTS bertujuan untuk mengurangi nyeri. Mekanisme pengurangan nyeri dengan efek non thermal yang terjadi pada ultrasound dapat memberikan stimulasi reseptor termal kulit atau peningkatan perluasan jaringan lunak sehingga dapat meningkatkan suhu jaringan dan merubah konduksi saraf dengan mengubah transmisi atau persepsi menyebabkan rasa nyeri.

Pada kelompok yang diberikan ultrasound serta ditambahkan Mobilisasi saraf medianus, carpal dan tendon gliding memberikan pengaruh penurunan nyeri yang significant. Hal ini sesuai dengan teori bahwa Latihan mobilisasi saraf medianus bertujuan untuk mengurangi nyeri dan meningkatkan LGS dimana mobilisasi saraf medianus bertujuan untuk meningkatkan mobilitas saraf medianus yang berguna untuk mengurangi nyeri dan meningkatkan LGS (Kisner, 2014), sedangkan Latihan tendon gliding yang bertujuan untuk memelihara dan meningkatkan mobilisasi tendon ekstrinsik serta koordinasi gerak. Penurunan nyeri pada kelompok ini lebih significant dikarenakan penggunaan kombinasi dari intervensi tersebut dimana memberikan latihan mobilisasi saraf medianus dapat membantu mengembalikan aliran pembuluh darah balik vena dari saraf medianus sehingga mengurangi tekanan di dalam epineurium sehingga dapat mengurangi nyeri dengan ditambah latihan tendon gliding dapat membantu mengembalikan aliran pembuluh darah balik vena dari saraf medianus sehingga mengurangi tekanan di dalam epineurium sehingga dapat mengurangi nyeri. Selain itu selama proses penelitian responden juga diajarkan home edukasi untuk melakukan perlindungan pada pergelangan tangan dengan mengurangi aktivitas yang menimbulkan nyeri seperti tidak membawa barang terlalu berat selama menjalani proses perawatan serta mengurangi penggunaan pergelangan tangan dan jari.

\section{KESIMPULAN}

Berdasarkan hasil penelitian menunjukkan bahwa ada pengaruh penambahan intervensi mobilisasi syaraf, mobilisasi carpal, dan tendon gliding setelah dilakukan ultrasound terhadap penururunan nyeri pasien CTS

\section{UCAPAN TERIMAKASIH (ACKNOWLEDGEMENT)}

1. Kepada segenap jajaran pimpinan STIKES Katolik St. Vincentius a Paulo yang telah memberikan ijin untuk melakukan proses penelitian.

2. Jajaran pimpinan RSUD sidoarjo yang telah memberikan kesempatan untuk pengambilan data khususnya di unit rehab medic.

3. Kegiatan penelitian ini sepenuhnya dibiayai oleh DRPM Kemenristekdikti 2019.

\section{DAFTAR PUSTAKA}

Arul, D. S. 2016. Effect of Kineso Tapping with Exercise Versus Ultrasound with Exercise on Pain Relief in Acute Carpal Tunnel Syndrome. Journal of Medical Science and Technology, 27.

Assad, M. S. 2017. Prevalence of Obesity in Carpal Tunnel Syndrome Patients: A Cross-Sectional Survey. BMC Muskuloskeletal Dissorder , 3-9.

Cameron, Michelle. 2009. Physical Agents in Rehabilitation.3th ed. Philadelphia:Saunders Elsevier.

Chan, Y.-W. 2014. Comparative effectiveness of ultrasound and paraffin therapy in patients with carpal tunnel syndrome: a randomized trial. BMC Musculosceletal disorders $15,399$.

Jurjević, A. B. 2010. Early onset of carpal tunnel syndrome during pregnancy: case report. Acta Clinica Croatica Vol 49 No $1,77-80$.

Kisner, Carolyn \& Colby, L. A. 2014. Therapeutic Exercise: Foundationand Technique. Philadelphia: F.A Davis Company. 
Kurniawan, Bina. 2008. Faktor Risiko Kejadian Carpal Tunnel Syndrome pada Wanita Pemetik Melati dan Keselamatan Kerja FKM UNDIP. Jurnal Promosi Kesehatan Indonesia.Volume 3, 31-37

Kowalak. 2011. Buku Ajar Patofisiologi. USA: Lippincont Williams \& Wilkins inc.

Lubis, A. A., Andriane, Y., \& Dewi, M. K. 2016. Karakteristik Pasien CTS (Carpal Tunnel Syndrome) di Rumah Sakit AlIslam Bandung periode 1 Januari 2011 31 Desember 2015. Prosiding Pendidikan Dokter, 574-580.

Mansour, A. M. 2011. Laser versus Nerve and Tendon Gliding Exercise in Treating Carpal Tunnel Syndrome. Life Science Journal Vol 8 No 2 , 413-420.

Robby, A. d. 2006. Hubungan Tingkat Keparahan Gejala dan Status Fungsional Pada Pasien Carpal Tunnel Syndorme diukur Menggunakan Carpal Tunnel
Syndorme Assessment . Jurnal Kedokteran Diponegoro Vol 5 No 3 , 20.

Sabhilia, Salsa \& Agus, Windharto. 2017. Desain Peralatan Memasak untuk Penderita Arthritis dan Carpal Tunnel Syndrome. Jurnal Sain dan Seni ITS. Volume 6. 69-73.

Saerang. 2015. Insiden Carpal Tunnel Syndrome Berdasarkan Anamnesis Pada Karyawan Bank di Kota Bitung Sulawesi Utara. Jurnal e-Clinical Vol 3 No 1, 13

Sayles. 2007. Standard of Care : Carpal Tunnel Syndrome. Carpal Tunnel Syndrome, 114.

Sjamsuhidajat, R. 2012. Buku Ajar Ilmu Bedah edisi 3. Jakarta: EGC.

Syahrul, S. d. 2014. Carpal Tunnel Syndrome. Jurnal Kedokteran Syiah Kuala Vol 14 No 1, 51.

Trisnowiyanto, Bambang. 2012. Instrumen Pemeriksaan Fisioterapi dan Penelitian Kesehatan. Jogjakarta: Nuha Medika 